\title{
Self-Assembled Monolayers of Mercaptoacetic Acid on Ag Powder: Characterization by FT-IR Diffuse Reflection Spectroscopy
}

\author{
Chinkap Chung* and Myunghee Lee \\ Department of Chemistry, Keimyung liniversity, Duegut 704-701, Korea \\ Received June 16, 2004
}

Key Words : Mercaptoacetic acid, SAM, FT-IR diffuse reflection spectroscopy

The self-assembled monolayers (SAMs) of orgamic molecules on metal surfaces have been studied extensively in recent years. ${ }^{1-4}$ Both carboxylic acids and thiols are known to be adsorbed on Ag surfaces forming well packed monolayers ${ }^{56}$ however, the competitive adsorption of thiols and carboxylic acids on Ag has not been reported much. ${ }^{7}$ To find out which group would be adsorbed preferentially on Ag surface when both thiol and carboxylic acid groups were present in the same molecule, we chose a bifunctional molecule, mercaptoacetic acid as the probe because it is the simplest molecule that contains both groups. Since the molecule has only one methylene unit, it would not have any interchain stabilization of the monolayer. The interaction between a head group and a metal substrate would be the main factor that controls the formation of the monolayer. We assume that the intermolecular hydrogen bonding which has been reported for a monolayer of $\omega$-mercaptocarboxylic acid on gold ${ }^{8}$ would also allect some influence in monolayer formation on silver if the carboxylic acid group is a tail group. Since silver powder was used as substrate for monolayer, we used FTIR diffuse rellection spectroscopy as a characterization tool which has been successlully applicd for the similar purpose before and the experimental details was similar to the previous report. ${ }^{7.9}$

Depending on the adsorbing group, the monolayer would have one of the three structures shown in Figure 1. The Figure 1(a) shows that the molecule is adsorbed as a carboxylate. This type of adsorption was observed for the monolayers of n-alkanoic acids on Ag surface, Various thiols are adsorbed on Ag surfaces as a thiolate such as shown in Figure 1(b). ${ }^{6}$ Another possibility is the structure with both thiol and carboxylate of the same molecule attached on the Ag surface as shown in Figure 1(c). Since mercaptoacetic acid has both groups, it could be adsorbed on $\mathrm{Ag}$ surface as one of the structures in the Figure or as the mixture of these structures.

Figure 2(b) shows the diffuse reflection spectrum of mercaptoacetic acid monolayer on Ag powder along with the transmission spectrum of the same molecule in liquid phase shown in Figure 2(a). Peak positions for specific vibrational modes were compared with previously reported values. ${ }^{9}$.16) Because the usual surface selection rule that

"Conesponding Author. Phone: 1 82-53-580-5535. Fux: $182-53-580$ 5164. e-mail: chinkap $a k$ knu.ac.kr (a)

(b)
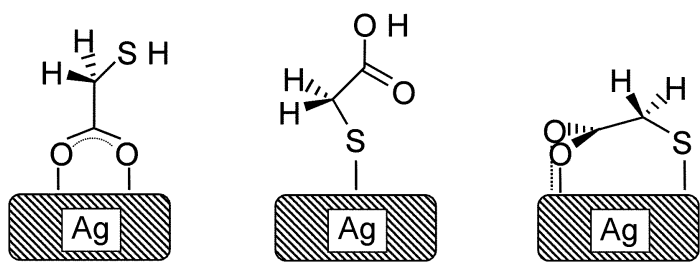

Figure 1. Schematic diagrams of the monolayer of mereaptoacetic acid adsorbed (a) with a carboxylate group on $\mathrm{Ag}$. (b) with a thiol group on $\mathrm{Ag}$, and (c) with both groups on $\mathrm{Ag}$.

applied to flat metal surlaces" was observed for the surface of metal powder, ${ }^{9}$ the vibrational modes of dipole parallel to the surface would vanish but those perpendicular to the surface would increase in the spectrum. In the liquid spectrum of a randomly oriented molecule shown in Figure 2(a), we observed the strong $v(\mathrm{C}-\mathrm{O})$ band at around 1720

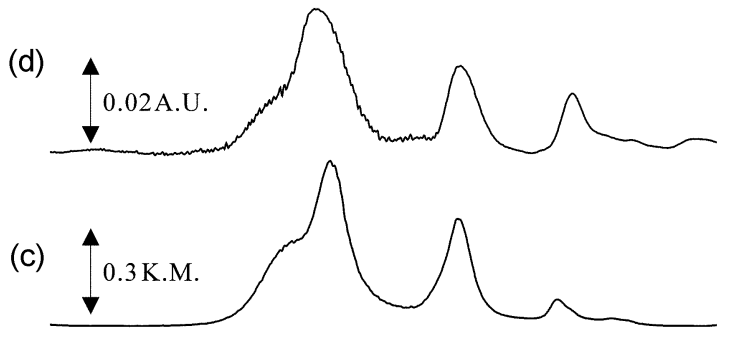

(b)
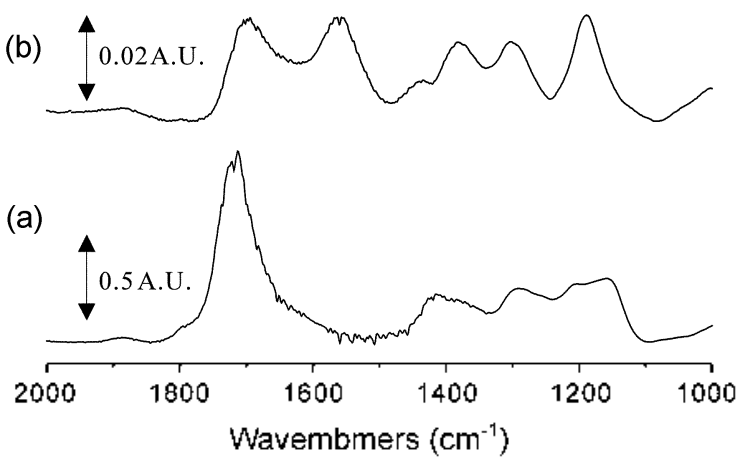

Figure 2. FTIR spectra of compounds: (a) neat mercaptoacetic acid in licunid phase, (b) the monolayer of mercaptoacetic actid on $\mathrm{Ag}$. (c) neat sodium mercaptoacetate diluted with $\mathrm{KBr}$ powder and (d) the monolayer of sodium mercaptoacetate on Ag. (a) is taken in transmission mode. and the others are taken in difluse rellection mode. 
$\mathrm{cm}^{-1}$ as well as weaker absorption bands at $1415,1292$. 1203 , and $1159 \mathrm{~cm}^{-1}$. In the monolayer spectrum shown in Figure 2(b). we noticed the appearance of $V_{\text {is }}\left(\mathrm{CO}_{2}^{-}\right)$band at $1560 \mathrm{~cm}^{-1}$ and $v_{\mathrm{s}}\left(\mathrm{CO}_{2}^{-}\right)$band at $138 \mathrm{I} \mathrm{cm}^{-1}$, which implied that some of the acid molecule is ionized during the formation of a monolayer. Shifts of other peaks were also observed such as $v(\mathrm{C}=0)$ band from 1720 to $1693 \mathrm{~cm}^{-1}$. It indicates the intermolecular hydrogen bonding of the carboxylic acid tail groups. Otherwise, the frequency for $v$ $(C=O)$ would be increased due to the breaking up of dimer structures of carboxylic acids. The presence of the peaks corresponding to $v(\mathrm{C}=\mathrm{O})$ and $v_{\mathrm{uts}}\left(\mathrm{CO}_{2}^{-}\right)$strongly supports the monolayer has the structure shown in Figure $\mathrm{I}(\mathrm{b})$. The carboxylic acid was known to be adsorbed on $\mathrm{Ag}$ as carboxylate after deprotonation. ${ }^{5.6}$ If the monolayer of mercaptoacetic acid existed as the structure shown in Figures 1 (a) or $1(\mathrm{c})$, only $\mathrm{V}_{5}\left(\mathrm{CO}_{2}^{-}\right)$mode at around 1400 $\mathrm{cm}^{-1}$ would be observed. The monolayers adsorbed on $\mathrm{Ag}$ with a carboxylic acid as the head group have a prominent peak for $v_{4}\left(\mathrm{CO}_{2}^{-}\right)$at around $1400 \mathrm{~cm}^{-1}$. However, the presence of the peaks for $v(\mathrm{C}=\mathrm{O})$ and $v_{\mathrm{uss}}\left(\mathrm{CO}_{2}^{-}\right)$modes has never been observed. The structures in Figure $I$ (a) and $I(c)$ would have $v_{\text {its }}\left(\mathrm{CO}_{2}^{-}\right)$modes parallel to the metal surface no matter what the tilt angle is, therefore the peak at around $1560 \mathrm{~cm}^{-1}$ corresponds to that mode would not show up in the spectrum. Because the two oxygen-carbon bonds in the Figure $\mathrm{l}(\mathrm{a})$ and Figure $\mathrm{l}(\mathrm{c})$ are equivalent, $v(\mathrm{C}=\mathrm{O})$ mode at around $1693 \mathrm{~cm}^{-1}$ and $v(\mathrm{C}-\mathrm{O})$ mode at around $1189 \mathrm{~cm}^{-1}$ would also vanish. The presence of these peaks in the monolayer spectrum of mercaptoacetic acid proves that the monolayer exists as structure $(b)$ in Figure 1.

Io assure that the molecule was adsorbed with a thiol group on $\mathrm{Ag}$. we made a monolayer of sodium mercaptoacetate. Figure 2(d) shows the diffuse reflection spectrum of sodium mercaptoacetate self-assembled on $\mathrm{Ag}$ powder. For comparison. we also showed the spectrum of the same molecule diluted with $\mathrm{KBr}$ powder on Figure 2(c). Figure 2(d) shows that the monolayer spectrum is very similar to the $\mathrm{KBr}$ spectrum of the molecule. In our previous experiment, normal carboxylic acid and its sodium salt produced the same monolayer. This means that if the carboxylate group were adsorbed on $\mathrm{Ag}$ as the head group. the structure of the resulting monolayer would be the same as that shown in Figure 1(a). In this case, only $v_{s}\left(\mathrm{CO}_{2}^{-}\right)$band at around $1400 \mathrm{~cm}^{-1}$ would have been observed as discussed above. However, the monolayer spectrum in Figure 2(d) clearly show a peak at $1603 \mathrm{~cm}^{-1}$, which is assigned as $V_{\text {iss }}\left(\mathrm{CO}_{2}^{-}\right)$mode. The presence of this peak supports that the thiol group of inercaptoacetate is adsorbed as the head group on $\mathrm{Ag}$ powder. The exact peak position of this $V_{\mathrm{is}}\left(\mathrm{CO}_{2}^{-}\right)$ mode is known to be very sensitive to the degree of hydrogen bonding of carboxylic group. ${ }^{12}$ Small amount of ionized carboxylate anong carboxylic acids in Figure 2(b) would be more hydrogen bonded than that of Figure 2(d), which would cause the absorption at lower frequency. Compared to the spectrum in Figure 2(b), the disappearance of $v(\mathrm{C}-\mathrm{O})$ peak at $1693 \mathrm{~cm}^{-1}$ and $v(\mathrm{C}-\mathrm{O})$ peak at $1189 \mathrm{~cm}^{-1}$
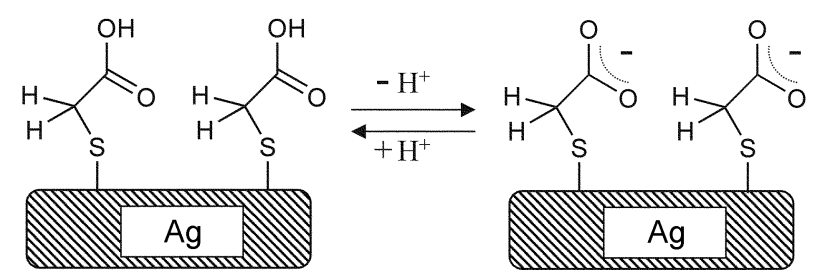

Figure 3. A schematic diagram for the acid/base treatment of the monolayers of mercaptoacetic acid and sodium mereaptoacetate. Sodium cations are not shown in the figure.

was observed, which resulted from the deprotonation of carboxylic acid.

If the carboxylic acid group were the tail group of the adsorbed molecule, the exposed carboxylic acid group would show the acid-base behavior depending on the environments. To confirm this, we soaked the $\mathrm{Ag}$ powder covered with a monolayer of mercaptoacetic acid in aqueous $0.5 \mathrm{M}$ sodium hydroxide solution for a few minutes, filtered, rinsed with absolute ethanol, and dried. When we took the DRIF"] spectrum of the treated monolayer, it was the same as that of sodium Inercaptoacetate as shown in Figure 2(d). It means that the proton of carboxylic acid is removed to leave carboxylate on the surface. We also tried the same experiment in reverse order. The peak positions and the absorption intensities of the resulting spectrum were almost the same as that shown in Figure 2(b), which indicates the protonation of the most carboxylates. This is illustrated in a scheme shown in Figure 3. This acid-base behavior is another evidence of carboxylic acid groups as a tail group in a monolayer.

From the above experiments, we clearly showed that the thiol moiety of mercaptoacetic acid was adsorbed on Ag powder exposing the carboxylic acid group on the surface. Experiments with longer alkyl chains are also on the way to show the interchain interaction effect on a competitive adsorption.

Acknowledgement. This work was carried out during the sabbatical leave of Chinkap Chung from Keimyung University.

\section{References and Notes}

1. Adsontion of Wolectles at Weral Sufaces: 1.ipkowski. I.: Ross. P. N.. I:ds: VC'Il Publishers: New York. 1992.

2. Chung. C.: Lee. M. J. Electroanal (hem. 1999. $\$ 68.91$.

3. Seo. K.: Jeon. 1. C.: Hong. H-G.: l'ark W. Bulf. Kortem ('he'm. Soc. 2002. 23. 1671.

4. Allara. D. L.: Nuzzo. R. G. Langmuir 1985. /. 45.

5. IJan, S. W.: I Ian, II. S.: Kim, K. Iib Spectrose 1999.2 2l, 133

6. Jao. Y. 'L.J. Am Chem. Soc. 1993. 115.4350.

7. Lee. M.: Park. K.: Chung. C. Butl. Korean Chem Soc 2000. 21. 532.

8. Sawaguchi. T.: Sato. Y.: Mizutani. F, f. Electrothel. Chem. 2001. 507.256 .

9. Ilan, II. S.: Kim, C. I1.: Kim, K. Appl, Sprectrose. 1998. 52. 1047.

10. I.estelius. M.: L iedberg. B.: Tengvall. P. Langmair 1997. 13.5900.

11. Hoflimann. F. M. Surf Soi. Rep. 1983. 3. 107.

12. Bellanny. L. J. The Infrared Spectra of ('omplex Holecules. $3^{\text {id }}$ Ed.: Chapman and Hall: London. 1975. 